\title{
BIBLIOTECAS ESCOLARES NO INTERIOR DO ESTADO DE SÃO PAULO: EVIDÊNCIAS SOBRE A CARÊNCIA DE RECURSOS
}

\section{Everton da Silva Camilo ${ }^{1}$ Claudio Marcondes de Castro Filho ${ }^{2}$}

\begin{abstract}
Resumo: Quando trazemos considerações sobre a existência de bibliotecas no território brasileiro, por vezes, se não frequentemente, nos deparamos com reflexões que se movem no campo da responsabilidade do Estado para com as iniciativas de políticas públicas contínuas nos campos da Educação e Cultura do País. Nesse sentido, a cidade de Ribeirão Preto, pertencente a uma das regiões mais ricas do Estado de São Paulo e que apresenta elevado padrão de vida e bons indicadores sociais, por não apresentar um coeso e interligado sistema de bibliotecas escolares, dado a magnitude desse município no interior do Estado de São Paulo, tornou-se a ambiência do objeto de estudo - bibliotecas escolares do sistema municipal de ensino de Ribeirão Preto - dessa investigação. À vista disso, objetivou-se analisar a possibilidade de uma rede de bibliotecas escolares ao sistema municipal de ensino de Ribeirão Preto. Para tanto, como metodologia, foi realizada uma pesquisa exploratória, descritiva, de natureza qualiquantitativa, com coleta de dados realizada a partir de técnica de observação simples durante visita técnica a quatro escolas do sistema municipal de ensino de Ribeirão Preto de diferentes regiões administrativas, assim como houve a aplicação de questionário aosresponsáveis das quatro bibliotecas escolares visitadas. Concluiu-se que as bibliotecas pesquisadas se encontram fora dos padrões estipulados pela política da International Association of School Librarianship, caso se anseie por bibliotecas escolares conectadas por meio de uma rede no sistema municipal de ensino de Ribeirão Preto. Abriu-se margem, assim, à discussão ao desenvolvimento de políticasmunicipais em favor de tornar as bibliotecas escolares das escolas do sistema municipal de ensino da cidade unidades de informação legitimadas e potencializadoras de formação de alcance global e de uso profícuo que objetive o desenvolvimento de novas competências e habilidades nos alunos.
\end{abstract}

Palavras-chave: Rede de bibliotecas. Biblioteca Escolar. Políticas Públicas. São Paulo. Ribeirão Preto.

\section{INTRODUÇÃO}

Quando trazemos considerações sobre a existência de bibliotecas no território brasileiro, por vezes, se não frequentemente, nos deparamos com reflexões que se movem no campo da responsabilidade do Estado para com as iniciativas de políticas públicas contínuas nos campos da Educação e Cultura do País.

1 Mestrando do Programa de Pós-graduação em Ciência da Informação da Universidade Estadual Paulista Faculdade de Filosofia e Ciências (UNESP/FFC/Marília) - Campus Marília. Bacharel em Biblioteconomia e Ciência da Informação pela Universidade de São Paulo (USP). E-mail: evertonscamillo@outlook.com

2 Pós-doutor em Biblioteca Escolar na Universidade Aberta de Lisboa. Doutor em Ciência da Informação pela Universidade de São Paulo (USP). Mestre em Ciência da Informação e Documentação pela Universidade de São Paulo (USP). Bacharel em Biblioteconomia pela Fundação Escola de Sociologia e Política de São Paulo. Professor Doutor do Departamento de Educação, Informação e Comunicação da Universidade de São Paulo - Faculdade de Filosofia, Ciências e Letrs de Ribeirão Preto (USP/FFCLRP) - Campus Ribeirão Preto. E-mail: claudiomarcondes54@gmail.com 
Logo, as bibliotecas, como equipamentos cultural-informacionais, representam condição indispensável à formação educativa e cultural, assim como são instrumentos que auxiliam no aperfeiçoamento da qualidade de vida e tomada de decisão (SUAIDEN, 1995). E a biblioteca escolar, como organização legitimada que trabalha com as perspectivas da informação, conhecimento e cultura, deve ser compreendido, essencialmente, como centro ativo do fazeraprender, onde o ensino e a aprendizagem têm livres caminhos.

Entretanto, nesse ínterim, é comum notarmos uma baixa dinamização do espaço de bibliotecas, sobretudo em escolas de ensinos fundamental e médio sob administração do poder público. Esses espaços de informação, recreação e conhecimento, se não aliançados à proposta do Projeto Político Pedagógico da escola, deixam de fomentar a experiência individual e coletiva dos discentes e docentes no processo de ensino-aprendizagem, tendo em vista os âmbitos cultural, educacional, social, político e humano.

Órgãos governamentais que estão incumbidos do desenvolvimento de políticas que se estendam ao campo da Biblioteconomia, assim como as escolas de Biblioteconomia e Ciência da Informação e associações de bibliotecários, têm grande peso nesse processo de desenvolvimento, que é marcado em seu início com a conscientização por parte das autoridades. Pois, "A responsabilidade sobre a biblioteca escolar cabe às autoridades locais, regionais e nacionais", sendo "apoiada por políticas e legislação específicas" (IFLA; UNESCO, 2000, p. 2).

Assim, problematizamos a possibilidade de formação de uma rede de bibliotecas escolares ao sistema municipal de ensino de Ribeirão Preto, no interior do Estado de São Paulo; uma empreitada que visa a maximização do poder intrínseco à existência de bibliotecas funcionantes mediante sua filosofia e espírito na instituição escolar, ora garantidos pela IFLA e UNESCO (2000; 2015).

Portanto, a pesquisa parte da seguinte indagação: é possível haver uma rede de bibliotecas escolares no sistema municipal de ensino de Ribeirão Preto?

Ribeirão Preto que é município pertencente a uma das regiões mais ricas do Estado de São Paulo. Apresenta elevado padrão de vida e bons indicadores sociais que "ancoram-se em uma estrutura econômica forte e diversificada tanto no município como na região" (BRASIL, 2018). O município também acaba por abarcar uma população de aproximadamente 654.893 habitantes. Desse valor, aponta-se um percentual de 17,82\% de população com menos de 15 anos de idade, isto é, cerca de 116.702 habitantes da população ainda em idade escolar, 


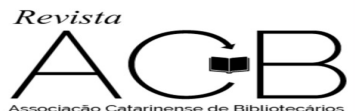

pertencentes, portanto, ao ensino fundamental do sistema municipal de ensino, segundo dados do último censo realizado em 2016, considerando a faixa etária escolar nacional (IMP, 2018).

Assim, Ribeirão Preto, fundada em 19 de junho de 1856, possui um dos maiores IDHs do Brasil, tendo alcançado uma taxa de 0,800 , de acordo com números obtidos na última análise referente ao ano de 2010 na página Informações dos Municípios Paulistas (IMP) (IMP, 2018).

Em vista das várias características desse município, anseia-se pelo desenvolvimento de políticas intramunicipais para mediação, acesso e uso da informação à sua ambiência, visando a melhoria da educação pública municipal no que tange à caracterização e legitimação das suas bibliotecas escolares, pois estas são instrumentos fomentadores, integradores e desenvolvedores da educação, cultura e vida política dos que nelas convivem.

Objetiva-se, portanto, analisar a possibilidade de uma rede de bibliotecas escolares ao sistema municipal de ensino de Ribeirão Preto, sendo que, para tanto, como metodologia, foi realizada uma pesquisa exploratória, descritiva, de natureza qualiquantitativa, com coleta de dados realizada a partir de técnica de observação simples durante visita técnica a quatro escolas do sistema municipal de ensino, assim como houve a aplicação de questionário aos responsáveis das quatro bibliotecas escolares visitadas.

\section{BIBLIOTECA ESCOLAR}

A biblioteca escolar, sendo um equipamento tanto informacional quanto cultural, trabalha com as perspectivas da informação, do conhecimento e da cultura. Isso faz com que ela emane, por assim dizer, sua imagem de lugar onde a aprendizagem toma livres caminhos. Pois ela é um espaço de aprendizagem por excelência onde ocorre a confluência dos saberes.

Para as Diretrizes da IFLA (2015), o ponto de convergência entre as bibliotecas escolares em todo o mundo tem a ver com um objetivo em comum: o reforço de que esta trabalha em prol do ensino e aprendizagem de todos no contexto escolar.

Embora a IFLA (2015) sugira, além dessa, outras perspectivas em torno do espírito, filosofia e essência das bibliotecas escolares ideais para o mundo, não é incomum denotarmos no cenário social atual Estados negligentes que não adotam preceitos norteadores em favor de desenvolver esses equipamentos cultural-informacionais. Pois, o que se inscreve no cerne dessas tipologias de unidades de informação auxilia na concepção da informação como um marco que, ora, há de ser trabalhada no âmbito escolar. 
Parece haver um suposto desconhecimento da estratégia da informação no marco da educação que, ao contrário, e por assim dizer, tem potencial para agir articuladamente com a política econômica e o desenvolvimento social do país (ZARDONI, 2012). Porém, é factual uma miopia frente a percepção do fazer da biblioteca escolar no meio em que se insere.

Desde 1999, Silva pontua que no Brasil, "Em primeiro lugar, quase não se tem notícia de medidas governamentais que visem à elevação das condições de funcionamento das bibliotecas das nossas escolas" (1999, p. 14), prevalecendo o silêncio em torno da questão da biblioteca escolar.

Vemos que as elites, por meio de mecanismos próprios, inibem os indivíduos ao alcance do dito-além-de-terceiros. O agir político que se supunha trabalhar em favor do alcance da emancipação do ser é visto como inscrito no acontecimento de uma inércia estatal frente a esse problema público, uma vez que essa noção requer que atores políticos passem a considerar, intersubjetivamente, um dado problema como uma situação adequada ou inadequada e de relevância ou não à coletividade

Assim, aproximadamente vinte anos após a publicação do seu livro, ainda concordamos veementemente com Silva (1999) em termos da miséria da biblioteca escolar, pois é impossível não reestabelecermos conexões com o atual cenário de 2018, percebendo a inércia para com esse problema que, todavia, se sustenta.

O estigma sobre bibliotecas escolares como depósitos de livros transita no meio social. Isso nada mais é do que fruto de uma convenção social pouco contornada pelo Estado que, por meio da sua inércia, corrobora o fato.

Ao contrário dessa percepção, a biblioteca escolar leva a noção de completude às atividades escolares. Logo, a escola se tornaria um instrumento imperfeito caso não dispusesse de uma biblioteca. Entretanto, a biblioteca sem o ensino seria apenas um instrumento vago e de incertezas, levianamente inscrito no âmbito educacional. Portanto, é inviável, por parte da escola, cumprir o seu papel sem que haja uma biblioteca como suporte às suas atividades-missão pedagógicas (PINHEIRO; SACHETTI, 2004).

Em vista disso, a partir das Diretrizes da IFLA (2015, p. 20, tradução nossa), a biblioteca escolar se constitui como:

a) "um espaço físico e digital na escola de aberto e acessível a todos";

b) "um espaço de informação proporcionando um acesso equitativo e aberto a fontes de informação de qualidade em todos os suportes e media, incluindo coleções impressas, multimídia e curadoria de conteúdos digitais"; 
c) "um espaço seguro onde são incentivadas e apoiadas a curiosidade individual, a criatividade e o desejo de aprender e onde os alunos podem explorar diversos assuntos, inclusive temas controversos, em privacidade e segurança";

d) "um espaço educativo onde os alunos aprendem as capacidades e atitudes para lidar com a informação e para a criação de conhecimento";

e) "um espaço tecnológico fornecendo uma gama diversificada de ferramentas tecnológicas, software e conhecimentos para a criação, representação e partilha de conhecimentos";

f) "um centro de competência, onde a comunidade escolar desenvolve a leitura e a competência em informação em todas as suas formas";

g) "um centro de cidadania digital, onde a comunidade escolar aprende a usar ferramentas digitais, de forma adequada, ética e segura, e aprende estratégias para proteger a identidade e informações pessoais";

h) "um ambiente de informação para todos os elementos da comunidade através do acesso equitativo aos recursos, tecnologia e desenvolvimento de competências de informação que nem sempre têm disponíveis em casa";

i) "um espaço social aberto a eventos culturais, profissionais e educativos (por exemplo, efemérides, encontros, exposições) para a comunidade em geral".

Sem esses ideais alcançados, uma oportuna biblioteca escolar dificilmente existirá, dando margem à existência da sua versão de subsistência. Pois, para efetivar essa ambiçãono meio social, recursos humanos, financeiros, físicos e de informação são, inquestionavelmente, necessários, assim como preveem Nascimento e Castro Filho (2007).

\section{MÉTODOS E PROCEDIMENTOS}

Analisar a possibilidade de uma rede de bibliotecas escolares ao sistema municipal de ensino de Ribeirão Preto permitiu-nos caracterizar esta pesquisa como exploratória. Não é exploratória pelo simples fato de ansiar por este entendimento desprovido de problematização, mas, ao contrário, por saber que, dado sua conjuntura municipal, Ribeirão Preto é uma cidade que dispõe de possibilidades numerosas para fomentar projetos que transformem, incrementem e favoreçam o desenvolvimento do seu sistema municipal de ensino, que engloba, portanto, as bibliotecas escolares. 


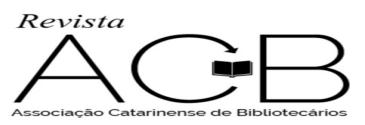

Isto nos move a determinar essa investigação como uma de iniciativa exploratória, considerando o objeto de estudo desta pesquisa - bibliotecas escolares do sistema municipal de ensino de Ribeirão Preto - pouco explorado no âmbito científico em que se insere a Biblioteconomia e Ciência da Informação como grandes áreas de estudo. Pois, Gil (1999, p. 27), ao que já afirmara, considera que "este tipo de pesquisa é realizado especialmente quando o tema escolhido é pouco explorado".

Assim, esta também é uma investigação descritiva e qualiquantitativa. Descritiva, pois apresenta dados coletados a partir da resposta de questionários respondidos por responsáveis das bibliotecas escolares visitadas, culminando na compreensão de uma realidade a partir da sua descrição quali e quantitativamente representadas.

Por outro lado, esta é, também, uma pesquisa qualiquantitativa, pois por meio das realidades compreendidas após a aplicação do questionário estruturado e técnica de observação simples, informações sobre a atuação e percepção de âmbito profissional dos responsáveis pelas unidades de informação, assim como dados ligados à infraestrutura dos recursos humanos, físicos, financeiros e de informação das bibliotecas visitadas, tornaram-se as informações o insumo dessa discussão, sendo representativas e descritivas quali e quantitativamente de realidades profissionais e estruturais.

Para tanto, usou-se da técnica de questionário, tendo sido elaborado um roteiro de perguntas como instrumento para coleta de dados e posteriormente aplicado junto aos responsáveis das bibliotecas escolares de quatro escolas públicas municipais de Ribeirão Preto, situadas uma em cada região administrativa. Também, utilizamos de visitas técnicas às bibliotecas e constatamos, por meio da aplicação de um roteiro de observação que endossa a técnica de observação simples, o universo dos recursos financeiros, humanos, físicos e informativos das bibliotecas escolares das escolas municipais de Ribeirão Preto.

Por técnica de observação simples, segundo Gil (2008, p.101),"entende-se aquela em que o pesquisador permanece alheio à comunidade, grupo ou situação que pretende estudar, observa de maneira espontânea os fatos que aí ocorrem" e que também "facilita a obtenção de dados sem produzir querelas ou suspeitas nos membros das comunidades, grupos ou instituições que estão sendo estudadas".

A infraestrutura da biblioteca escolar, segundo as Diretrizes da IFLA (2015) e da Declaração Política da IASL (2003), deverá atender os seguintes requisitos:

a) Espaços localizados próximos de onde há maior circulação e espaços de fácil acesso a todos usuários; 


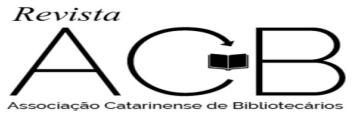

b) Iluminação adequada e suficiente, por meio de fonte natural e artificial;

c) Temperatura e umidade ambiente apropriada (ar condicionado) e monitorização (termohigrômetro), garantindo a preservação das coleções;

d) Tratamento acústico de portas e piso;

e) Dimensão adequada, possibilitando espaço para: coleção de livros, mídias e outros formatos; zonas de balcão de atendimento; zonas de estudo e leitura; zonas de produção e trabalho em grupo.

Logo, tais requisitos embasaram a elaboração do roteiro de observação para emprego da técnica de observação simples nas bibliotecas visitadas. Com isso, buscou-se perspectivar o enquadramento dos requisitos sugeridos pelas Diretrizes da IFLA (2015) e pela Declaração Política da IASL (2003) à ambiência das bibliotecas investigadas.

\section{ANÁLISE DOS RESULTADOS}

\section{Recursos Financeiros}

Recursos financeiros para quê, afinal? A biblioteca escolar, como instituição social, deve ter recursos suficientes para assegurar a existência de pessoal com formação adequada, documentos, tecnologias e equipamentos. Na opinião de Macedo (2005), a biblioteca deve contar com verbas próprias que visem a manutenção regular e as inovações necessárias ao melhor funcionamento da biblioteca; este é um compromisso que deve vir no orçamento geral da unidade escolar.

Pontualmente, as Diretrizes da IFLA para biblioteca escolar (IFLA, 2015) apontam componentes do plano orçamentário para o coeso funcionamento deste equipamento informacional.

Coube perguntar aos entrevistados: na cidade de Ribeirão Preto, existe direcionamento de verba à melhoria das bibliotecas escolares da rede municipal de educação?

Embora os entrevistados desconhecessem o fato de haver direcionamento de dinheiro às bibliotecas sob sua responsabilidade, observou-se que as quatro unidades visitadas subsistiam em termos de recursos físicos e de informação, o que indica que não há investimento que expect e elevar a estrutura funcional desses ambientes, sobretudo em termos de recursos físicos e de informação, dado que os recursos humanos, nessa conjuntura 


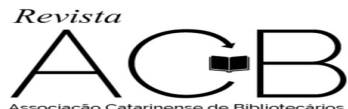

discutida - de escolas municipais - estão para outra abordagem em termos de discussão em vista do tipo e modo de contratação como servidor público.

Logo, aponta-se uma falta de compromisso da administração municipal dessas unidades de informação em relação a perspectivas de aplicação de recursos financeiros num cenário biblioteconômico da rede municipal de ensino que carente de inovações.

As Diretrizes da IFLA (2015) propõem que a atualização e vitalidade da coleção de recursos educativos e de informação de uma biblioteca escolar só é possível frente a uma postura de orçamento adequado, tendo observado a realidade local e suas demandas. Pois as despesas devem estar aliançadas e relacionadas com o que o Projeto Pedagógico da escola prevê.

Nessa lógica, observa-se que levar em conta tais aspectos supracitados traduz-se em investimento tanto aos professores e demais profissionais não docentes quanto aos alunos, instigando a biblioteca escolar a alcançar o seu objetivo no meio escolar.

Mas, financeiramente falando, esse objetivo só pode ser alcançado caso haja despesas orçamentais cuidadosamente planejadas para todo o ano e relacionadas com planos de ação, além de relatórios anuais que possam endossar a indicação da quantidade de dinheiro gasto com o programa da biblioteca escolar para cobrir ações e alcançar seu objetivo (IFLA, 2015, 28), corroborando que no município de Ribeirão Preto, portanto, talvez não haja sucesso no que tange ao alcance do objetivo das bibliotecas escolares nas escolas municipais em vista da não preocupação de que muito se pode fazer e alcançar quando há direcionamento financeiro para financiar o programa da biblioteca escolar, quer seja por meio da criação de (novos) produtos e serviços.

\section{Recursos Humanos}

Em se tratando de elementos-chave dentro de uma biblioteca escolar, o Manifesto da IFLA/UNESCO para biblioteca escolar (IFLA; UNESCO, 2000) apresenta considerações sobre os recursos humanos especificamente neste tipo de unidade de informação.

O documento expressa que o quadro de recursos humanos de uma biblioteca escolar deve ser composto por profissional da área de biblioteconomia, qualificado e responsável por planejar e administrar a unidade de informação. Além disso, sugere ainda que este profissional tenha uma equipe auxiliar que suporte o conjunto de responsabilidades a que se presta a biblioteca escolar. 


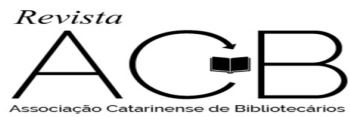

Ao verificarmos a formação e o grau de escolaridade dos responsáveis pelas bibliotecas visitadas, encontramos profissionais com formação inadequada, como visto no gráfico 1, pois estes não têm formação em Biblioteconomia - gráfico 2 -, o que é uma exigência legal,para ser responsável por bibliotecas.

\section{Gráfico 1 - Grau de escolaridade do responsável pela biblioteca escolar}

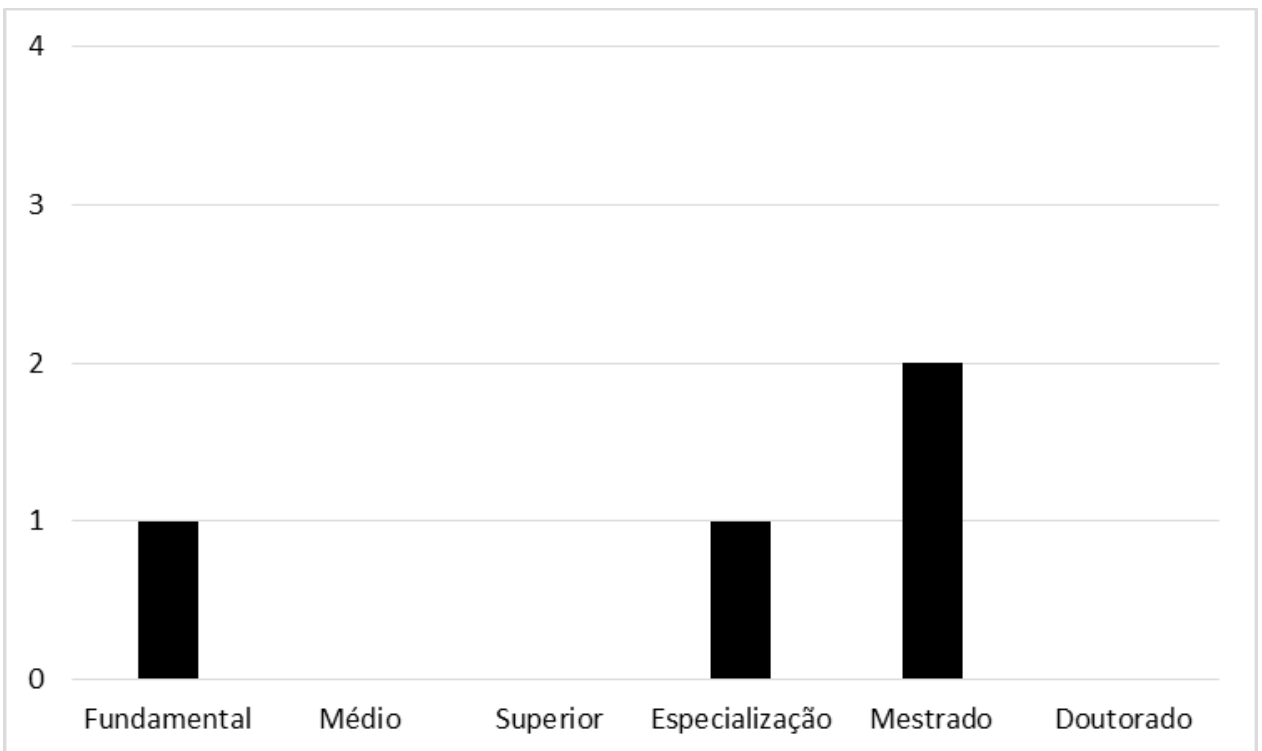

Fonte: Elaborado pelos autores (2018).

Como observado, durante a coleta de dados o grau de escolaridade variou entre ensinos fundamental e superior.

No quesito ensino fundamental, houve uma ocorrência. Já no ensino superior, três foram as ocorrências, sendo uma de especialização escolar e as outras duas em nível de mestrado: uma em história e a outra em biologia.

A interação entre a equipe da biblioteca e a equipe pedagógica acontece em diversas situações: nas práticas de leitura, no desenvolvimento de parcerias entre o corpo docente e demais profissionais a partir de uma abordagem dotada de multiversalidade. Tudo em favor do estímulo à educação.

Nesse sentido, é notória a importância que tem o envolvimento da equipe da biblioteca escolar com a equipe pedagógica durante o planejamento das atividades anuais que delineiam as rotinas escolares. Tal envolvimento é importante para que se diversifiquem em ações específicas de aprendizagem; para que se ampliem a promoção literária e a formação de 


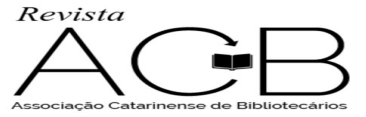

Revista ACB: Biblioteconomia em Santa Catarina, Florianópolis, v. 23, n. 2, p. 206-223, abr./jul., 2018.

leitores; para que tenha condição própria de elaborar a pesquisa e competência em informação para aprendizagem ao longo da vida.

$\mathrm{Na}$ pesquisa, encontramos profissionais que não participam das reuniões pedagógicas, de planejamento escolar e de professores, o que dificulta no desenvolvimento de ações importantes ao processo ensino-aprendizagem.

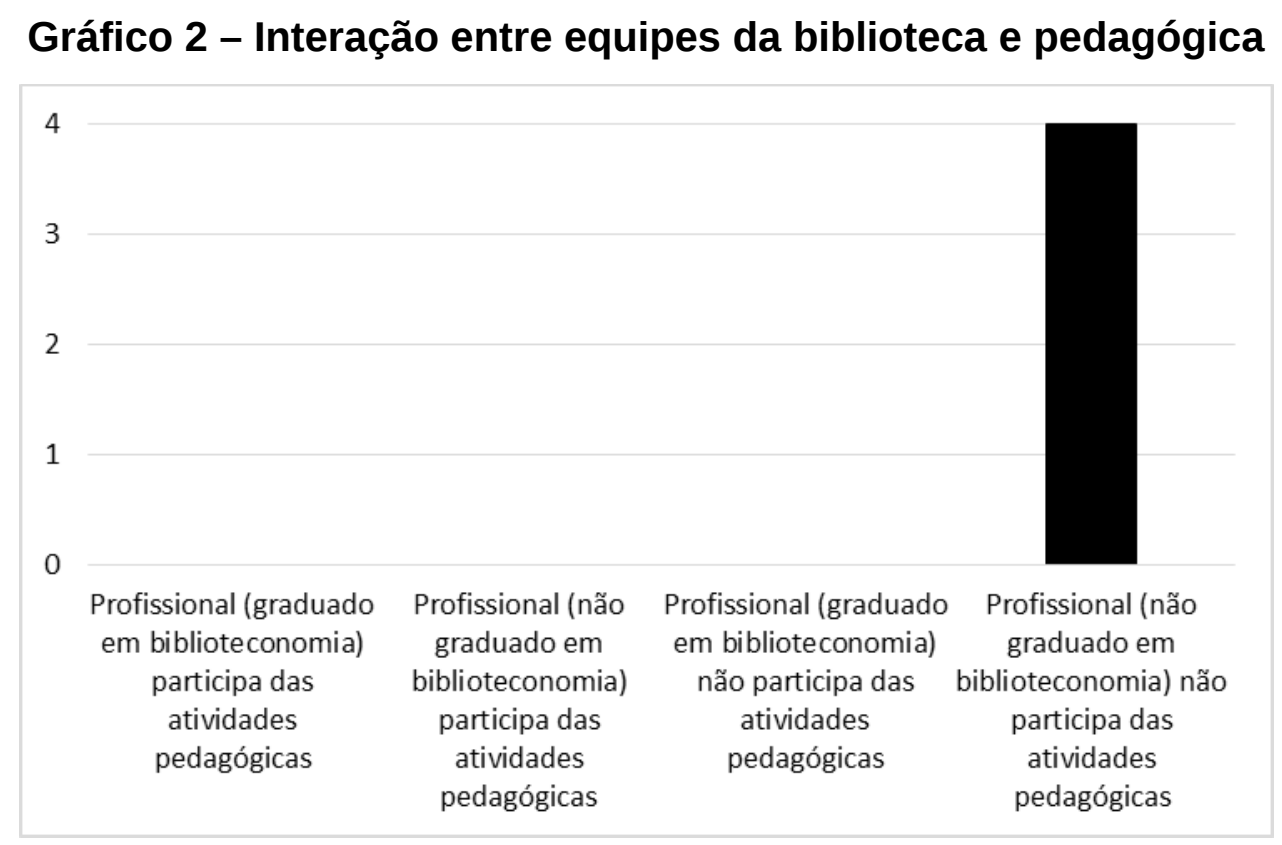

Fonte: Elaborado pelos autores (2018).

\section{Recursos Físicos}

Os recursos físicos de uma biblioteca são recursos indispensáveis à existência e ao pleno funcionamento de uma unidade de informação. O estabelecer de uma estrutura física à biblioteca escolar revela condição fundamental para o bom atendimento prestado por esta unidade.

A aparência estética do ambiente promove a sensação de acolhimento da comunidade escolar, ocasionando o incentivo à permanência na biblioteca (IFLA, 2015). Tais recursos podem englobar: mobiliário, instalações físicas, equipamentos, recursos materiais e de escritório, e consumo em geral (NASCIMENTO; CASTRO FILHO, 2007).

Como observado durante a visita às quatro bibliotecas escolares, verificou-seque a biblioteca escolar está longe de ser um ponto de referência dentro da escola, dificultando o seu agir como porta de entrada do ambiente escolar, fato que, de forma contrária, geraria o maior Revista ACB: Biblioteconomia em Santa Catarina, Florianópolis (Brasil) - ISSN 1414-0594 


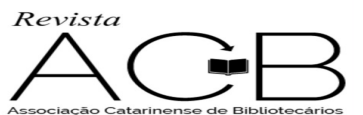

despertar de interesse na comunidade escolar como um todo caso sua localização fosse privilegiada e estivesse aliançada a projetos dentro da mesma, com produtos e serviços, o que vem justamente ao contrário do que afirma FEBAB (2011, p. 1), "[...] as bibliotecas e outras instituições relacionadas com a informação devem estabelecer parcerias para ações estratégicas e políticas públicas envolvendo o sistema de educação obrigatória", que, neste caso, parecerias entre a biblioteca e a equipe pedagógica.

Portanto, quanto a facilidade de acesso às bibliotecas, não existe nas quatro escolas. É importante ressaltar as gravidades geradas em função dessa anomalia presente na estrutura das bibliotecas escolares de Ribeirão Preto, pois o fato delimita e impede o que se busca por meio da acessibilidade e, consequentemente, do direito de acesso à informação nesse ambiente, como também a falta da inclusão social, cultural e educacional dos educandos. Pois a biblioteca é uma instituição "como o centro dinâmico de informação da escola, que permeia o seu contexto e o processo ensino-aprendizagem, interagindo com a sala de aula, que dispõe de recursos informacionais adequados" (ANTUNES, 1998, p. 87).Não ter acesso implica outros contextos graves e importantes discussões.

Com relação à sinalização da biblioteca no espaço escolar, apenas em um caso houve sinalização, entretanto, pouco visível. Nos outros três casos, havia a ausência.

Percebermos a biblioteca escolar, assim como qualquer outra unidade de informação, sem o devido norteamento por meio da sinalização viola os princípios de clareza, orientação e acessibilidade ao espaço físico, pois a biblioteca é um organismo que deve ser constituído para ser visível alcançável e atingível.

Continuando a verificação, perguntamos sobre a qualidade do ambiente das bibliotecas. Desse modo, embasamo-nos no sentido de estética, denotado por Carani (2000, p.169): "os aspectos estéticos também, no sentido de beleza e harmonia estética do ambiente, proporcionando um clima de encanto e graça".

Nas escolas pesquisadas não encontramos um ambiente acolhedor, inovador e agradável, mas sim lugares com espaços não funcionais, alguns sendo salas de aulas adaptadas com algumas estantes, opostos a um espaço "comunitário - um lugar para a troca de ideias e para a criação de conceitos inteiramente novos" (LANKES, 2016, p.131).

Dentro da amostra analisada, de forma geral, as escolas não contam com espaços onde se desenvolve atividades ligadas à leitura. Dessa forma, questionamentos têm ocorrido sobre o desenrolar de atividades ligadas ao desenvolvimento de habilidades leitoras às crianças das comunidades escolares analisadas. 


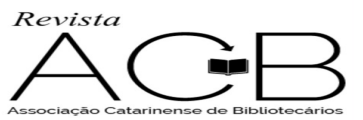

Assim, é oportuno afirmar que o ambiente das bibliotecas visitadas não provoca o interesse pela leitura e o instigar de uma imaginação fértil ao empenho de ações de prática de leitura e aprendizado como um todo. Isso porque os ambientes não são agradáveis, acolhedores, climatizados e tampouco estéticos, além do que dispõem de deplorável leiaute que não privilegia o espaço útil de trabalho. Nesse aspecto, podemos apresentar alguns itens em que uma biblioteca escolar pode fazer diferenças.

Nas palavras de Faulkner-Brown (1999), uma biblioteca deve ser com relação ao espaço: a) flexível; b) compacta; c) acessível; d) suscetível de ampliação: salas, acervo, recursos tecnológicos; e) variada; f) organizada; g) confortável; h) em meio ambiente constante com relação a temperatura; i) segura; j) econômica.

No sentido de verificar a existência específica do setor de referência, constatamos que em $50 \%$ das escolas visitadas há o balcão de atendimento. Dado isto, em duas das bibliotecas existe o mobiliário necessário à biblioteca escolar que, como descrevem Côrte e Bandeira (2011, p.25), é composto de: "estantes, mesas, cadeiras, escadas, balcão de empréstimo, bibliocantos, fichários, arquivos verticais, expositores para livros, revistas e vídeos, quadro de avisos, poltronas, guias de prateleiras de estantes, mapotecas, etc.".

Observamos que em três casos há a existência de estantes no espaço da biblioteca, mas em um caso não. Neste último, como evidenciado, armários são embutidos na parede, com poucos e sobrepostos livros à disposição. Todos os armários permaneciam sob tranca.

Com relação às tecnologias de informação e comunicação, deparamo-nos com a não existência de televisão, aparelhos reprodutores de DVD nem aparelhos reprodutores de CD em todas as escolas visitadas, o que impede, em parte, dar suporte às atividades lúdicopedagógicas das bibliotecas. No entanto, verificamos a existência em duas bibliotecas com computadores conectados à internet, disponibilizados aos alunos para algum tipo de pesquisa direta ou mediada pelo responsável pela biblioteca. Noutros dois casos, não há acesso à internet.

Para Lankes (2016, p. 116) "a nova visão da biblioteca não é local ou como acervo de livros, mas como uma plataforma comunitária para a criação e o compartilhamento de conhecimento", ou seja, a biblioteca tem que transcender o seu espaço, tem que estar sintonizada com o mundo contemporâneo do usuário e se atualizar com os mecanismos das novas tecnologias, seja para pesquisa ou para organização da informação, uma vez que as tecnologias de informação e comunicação fazem parte do cotidiano das pessoas. 


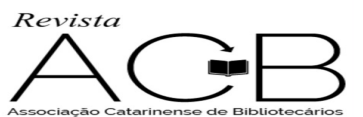

\section{Recursos de Informação}

Quando tratamos dos recursos de informação, Ramos (1996) descreve que os recursos passam a compreender todas as fontes de informação internas ou externas, acessíveis a partir desta unidade, quer sejam bibliográficas ou não. Para Macedo (2005), pensar o acervo como um conjunto de coleções é pensá-lo em sua formação, abarcando as variadas tipologias de publicação e documentação.

O Manifesto da IFLA/UNESCO para biblioteca escolar (IFLA; UNESCO, 2000) preconiza que o acervo deve ser composto por uma diversificação de materiais tais como livros e outras fontes de informação, podendo englobar obras de ficção a documentários em suas formas impressa ou eletrônica, presencial ou até mesmo remota.

Com relação à utilização da biblioteca, seja para consulta, para pesquisa ou para empréstimos, constatamos, por meio do questionário, que por parte dos alunos a biblioteca é pouco e razoavelmente utilizada, algo que vai contra o Manifesto da IFLA/UNESCO. Também por meio do questionário, constatamos que em uma das unidades visitadas o uso da biblioteca por professores é razoável, enquanto que noutros três, revelou-se pouco usada.

Nesse aspecto, para Corrêa et. al. (2002, p. 112), os principais objetivos e serviços da biblioteca escolar visam: cooperar com o currículo escolar; proporcionar aos usuários materiais diversos e serviços informacionais adequados; orientar e estimular os alunos em todos os aspectos da leitura. Somado a isso, a falta de um profissional adequado na biblioteca, ou seja, de um bibliotecário, reduz as chances de otimizar os recursos de informação nestes ambientes, justamente por este ser o profissional com competências específicas na organização, mediação e disseminação do acervo.

No aspecto da organização da informação nas bibliotecas pesquisadas, a maioria não atende as regras biblioteconômicas, pois, segundo as Diretrizes da IFLA para Bibliotecas Escolares (2015) é importante haver a escolha de uma aplicação informática que possa fazer a gestão do catálogo da biblioteca de forma adequada, visando à classificação e catalogação dos recursos. Notoriamente, isso facilita a sua integração com redes mais amplas de/em vários lugares do mundo.

A maioria das bibliotecas pesquisadas, ou seja 75\% delas, não tem o acervo registrado, classificado ou catalogado, o que impede o compartilhamento de informações com a comunidade escolar e com a comunidade externa. Esta não-organização da informação pode ser avaliada pela falta de um profissional bibliotecário que, neste contexto, tem papel 


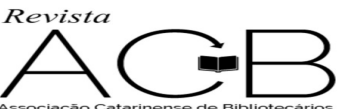

fundamental para incentivar a leitura pelas crianças e adolescentes, desenvolvendo atividades extracurriculares que proporcionem a criatividade, a reflexão e o pensamento crítico. A ausência deste profissional, entre outras complicações incutidas ao ambiente biblioteconômico, impede que bibliotecas estejam preparadas para direcionar o seu acervo as especificidades de cada leitor.

Perguntamos sobre a existência da informatização do acervo e o acesso remoto do catálogo e constatamos que apenas uma biblioteca pesquisada tem parte do acervo inserido em catálogo informatizado, ao passo que as restantes não. Entretanto, nos quatro casos, constatou-se que não há possibilidades de acesso remoto aos catálogos, mesmo o que está informatizado.

Com relação a existência de blog ou site da biblioteca não os encontramos em nenhuma biblioteca pesquisada. Não há nenhuma forma de comunicação da biblioteca com a sua comunidade externa no intento de se fazerem claras a sua missão, visão e valores e atuação como organismo social que trabalha com a informação e o conhecimento. Vê-se que todas as unidades de informação não dispõem de canal/ambiente virtual que funcione como mediador entre o que ocorre em termos de produção no ambiente interno e sua externalização à comunidade.

\section{CONSIDERAÇÕES FINAIS}

A biblioteca escolar é mais que do que tem pragmaticamente sido: vai além de aglomerações de recursos físicos, transpõe recursos informativos defasados e inutilizáveis. Ela é o palco de atuação de um corpo profissional multidisciplinar encabeçado pelo bibliotecário e naturalmente necessita de investimento para garantir a coesão, razão e propósito de sua existência.

Em âmbito de pragmatismo, temos visto depósitos de livros travestidos de um conceito que em nada é assegurado àquilo que querem que seja percebido. Como Gasparini (2016) já apontara, o Estado é genitor do seu próprio modelo de políticas, pois existem fatores intrínsecos à dinâmica do governo e sua relação com a sociedade, logo "para cada modelo de Estado e de governo haverá um conjunto próprio e coerente de políticas públicas" (GASPARINI, 2016, p. 25).

Isso chama a atenção à urgência do desenvolvimento de políticas públicas ribeirãopretanas que deem conta de abarcar, planejar e executar problemáticas concernentes à 


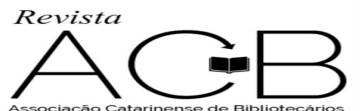

realidade das bibliotecas escolares do seu sistema municipal de ensino, pois este imerso num panorama de transitoriedade social há a demanda de repensar de ações que dialoguem com a proposta social que se desenha na contemporaneidade, com novos modos de mediar, gerenciar e usar a informação.

Caso queiramos imaginar as bibliotecas escolares presentes num contexto de alta sofisticação de uso, circundadas pelo mover de uma sociedade amparada na informação, conhecimento e trabalho de conectividade, como uma rede, buscar-se-á, então, o agir intermunicipal em favor de tornar essas unidades de informação legitimadas e potencializadoras de uma formação de alcance global e de uso profícuo ao desenvolvimento de novas habilidades àqueles que dessas ambiências informacionais fazem parte.

A International Association of School Librarianship (IASL) - Declaração Política da IASL sobre Bibliotecas Escolares (1993) - sugere que bibliotecas escolares necessitam, além de espaço adequado, de tecnologias para preparo, processamento e armazenamento de todos os materiais, bem como espaço que propicie o uso de materiais para leitura e manuseio, assim como recuperação de informação, por professores e estudantes. Portanto, à sua luz, concluímos que as bibliotecas pesquisadas se encontram fora dos padrões estipulados pela política da IASL.

\section{REFERÊNCIAS}

AMATO, M.; GARCIA, N. A. R. A biblioteca na escola. In: GARCIA, E. G (Coord). Biblioteca escolar: estrutura e funcionamento: São Paulo: Loyola, 1989, p. 9-23.

ANTUNES, W. A. Biblioteca escolar no Brasil: reconceituação e busca de sua identidade a partir de autores do processo ensinoaprendizagem. 1998. Tese (Doutorado em Educação) Faculdade de Educação da Universidade de São Paulo, 1998.

BRASIL. Ribeirão Preto. Dados econômicos. 2018. Disponível em: <http://www.ribeiraopreto.sp.gov.br/crp/dados/i01principal.php>. Acesso em: 15 jun. 2018.

CARANI, M. Arte e biblioteca: uma combinação perfeita!. Revista ACB: Biblioteconomia em Santa Catarina, v. 5, n. 5, p. 168-184, 2000. Disponível em: <http://www.brapci.inf.br/v/a/1407>. Acesso em: 05 jan. 2018.

CORRÊA, E. C. D. et. al.Bibliotecário escolar: um educador?.Rev. ACB: Biblioteconomia em Santa Catarina, Florianópolis, v. 7, n. 1, 2002, p. 107-123.

CORTE, A.; BANDEIRA, S. P. Biblioteca Escolar. Brasília: Briquet de Lemos / Livros, 2011. 


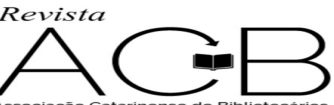

FAULKNER-BROWN, H. Design de grandes edifícios para bibliotecas. In: A Informação: tendências para o novo milênio. Brasília: IBICT, 1999. p.82-93.

FEBAB - FEDERAÇÃO BRASILEIRA DE ASSOCIAÇÕES DE BIBLIOTECÁRIOS. Declaração de Maceió sobre competência em informação: cenários e tendências. In: Congresso

Brasileiro de Biblioteconomia, Documentação e Ciência da Informação, 24., 2011, Maceió. Maceió: FEBAB, AAPB, 2011. Disponível em: < http://www.febab.org.br >. Acesso em: 01 set. 2017.

GASPARINI, E. Políticas públicas e intencionalidade. In: CHRISPINO, A. Introdução ao estudo das políticas públicas: uma visão interdisciplinar e contextualizada. Rio de Janeiro: FGV Editora, 2016.

GIL, A. C. Métodos e técnicas de pesquisa social. São Paulo: Atlas, 2008.

GIL, A. C. Métodos e técnicas de pesquisa social. 5. ed. São Paulo: Atlas, 1999.

IFLA - INTERNATIONAL FEDERATION LIBRARY ASSOCIATIONS AND INSTITUTIONS. IFLA School Library Guidelines. 2. ed. Haag: IFLA, 2015. Disponível em: $<$ https://www.ifla.org/files/assets/school-libraries-resource-centers/publications/ifla-schoollibrary-guidelines.pdf>. Acesso em: 01 jul. 2017.

IFLA - INTERNATIONAL FEDERATION LIBRARY ASSOCIATIONS AND INSTITUTIONS; UNESCO - ORGANIZAÇÃO DAS NAÇÕES UNIDAS PARA A EDUCAÇÃO, CIÊNCIA E A CULTURA. Manifesto IFLA/UNESCO para biblioteca escolar. Tradução: Neusa Dias de Macedo. São Paulo: IFLA, 2000. Disponível em:

<http://archive.ifla.org/VII/s11/pubs/portuguese-brazil.pdf>. Acesso em: 07 jul. 2017.

IMP - INFORMAÇÕES DOS MUNICÍPIOS PAULISTAS. Ribeirão Preto. 2018. Disponível em: <http://www.imp.seade.gov.br/frontend/\#/perfil>. Acesso em: 15 jun. 2018.

INTERNATIONAL ASSOCIATION OF SCHOOL LIBRARIANSHIP. Declaração política da IASL sobre bibliotecas escolares, 1993.

LANKES, D. R. Expect more: melhores bibliotecas para um mundo complexo. São Paulo: FEBAB, 2016.

MACEDO, N. D. (Org.). Biblioteca escolar brasileira em debate: da memória profissional a um fórum virtual. São Paulo: Editora Senac, 2005.

NASCIMENTO, A. M.; CASTRO FILHO, C. M. Retrato das bibliotecas escolares da rede estadual de ensino do município de Ribeirão Preto - SP. Biblionline, João Pessoa, v. 3, n. 1, 2007. Não paginado. Disponível em: <http://periodicos.ufpb.br/index.php/biblio/article/view/1496 >. Acesso em: 26 ago. 2017.

PINHEIRO, M. I. S.; SACHETTI, V. F. P. Classificação em cores: uma alternativa para bibliotecas infantis. In: SEMINÁRIO BIBLIOTECA ESCOLAR: espaço de ação pedagógica, 3., 
2004, Belo Horizonte. Anais... Belo Horizonte: UFMG, 2004. Disponível em: <http://gebe.eci.ufmg.br/downloads/319.pdf>. Acesso em: 08 jan. 2018.

RAMOS, P. B. A gestão na organização de unidades de informação. Ciência da Informação, Brasília, v. 25, n. 1, 1996. Diponível em: <http://revista.ibict.br/ciinf/article/view/671/680>. Acesso em: 28 set. 2017.

SILVA, W. C. Miséria da biblioteca escolar. São Paulo: Cortez, 1999.

SUAIDEN, E. Biblioteca pública e informação à comunidade. São Paulo: Global, 1995.

ZARDONI, H. C. ¿Sonnecesarias políticas públicas sobre la biblioteca escolar? Situaciónen América Latina. Biblios, n. 48, 2012, p. 21-29. Disponível em:

<https://biblios. pitt.edu/ojs/index.php/biblios/article/view/62>. Acesso em: 08 jan. 2018.

\title{
SCHOOL LIBRARIES OFSAO PAULO STATE INTERIOR: EVIDENCE ON LACK OF RESOURCES
}

\begin{abstract}
When we consider the existence of libraries in brazilian territory, sometimes, if not often, we are faced with reflections that move in the field of State responsibility towards the initiatives of continuous public policies in the fields of Education and Culture of a country. Ribeirão Preto, which belongs to one of the richest regions of the State of São Paulo and has a high standard of living and good social indicators, became the ambience of the object of study of this research. Due to this, the objective of this study was to analyze the possibility of a network of school libraries to the municipal education system of Ribeirão Preto. As a methodology, an exploratory, descriptive, qualitative and quantitative research was done with data collection performed using simple observation technique during a technical visit to four schools of the Ribeirão Preto's municipal education system from different administrative regions, as well as a questionnaire was applied to each head of each four school libraries visited. It was concluded that the libraries cannot be on the standards set by the policy of the International Association of School Librarianship. So, this led to the discussion of the development of municipal policies in favor of making the school libraries units of information legitimized and empowered aiming at the development of new skills and abilities in students.
\end{abstract}

Keywords: Networked Libraries. School Library. Public Policy. Sao Paulo. Ribeirão Preto.

RECEBIDO: 09-01-2018

ACEITO: $16-07-2018$ 